\title{
Surface properties of graphene and graphene/diamond composites located at a substrate with tungsten carbide doped by metals composites
}

\author{
Konrad Terpiłowski ${ }^{1}$ (D) Magdalena Szaniawska ${ }^{1}$
}

Received: 6 December 2018 / Revised: 4 February 2019 / Accepted: 7 February 2019 / Published online: 22 February 2019

(c) The Author(s) 2019

\begin{abstract}
The basis of the obtained materials was $95 \%$ (wt $\%$ ) tungsten carbide with the addition of about $4.75 \% \mathrm{Co} 0.1 \% \mathrm{Nb}$ and $0.15 \% \mathrm{Tl}$. During sintering flake graphene was added and in the case of the second sample also nano diamonds were added into the top layer. Surface properties of the obtained materials were determined by wettability. The apparent surface free energy was described applying the hysteresis approach. For better description of wettability the equilibrium contact angles, calculated from the Tadmor's theory, were used. Surface roughness of the obtained materials was examined using the optical profilometry. Generally, the obtained materials have a rough structure in the micrometer scale also exhibiting some nano roughness. The industrial tests show $15 \%$ durability improvement of these materials compared to those without graphene.
\end{abstract}

Keywords Graphene $\cdot$ Surface free energy $\cdot$ Wettability

\section{Introduction}

Graphene is an allotropic form of carbon with a two-dimensional structure. This structure provides outstanding properties of graphene material: mechanical, electrical, thermal and optical. Graphene dispersions were deposited using the drop casting method. Topography of the obtained materials was investigated by AFM microscopy and based on the $\mathrm{R}_{\mathrm{RMR}}$ index. The roughness of the obtained materials did not exceed $900 \mathrm{~nm}$. Existence of graphene was confirmed by Raman spectroscopy. Surface wettability was determined by $5 \mu \mathrm{l}$ water droplets measuring advancing and receding contact angles. The value of the advancing contact angle change from 65.62 to $139.69^{\circ}$ depending on the graphene functionalization (Marcano et al. 2010; Hadad et al. 2014; Quintana et al. 2010). A high contact angle hysteresis was observed on the obtained materials. Using this type of synthesis stable in time layers with controlled wettability were obtained. Zhao et al. (2017) obtained the graphene-metal hybrid system in five steps. On the composite surface uniform nanoscale

Konrad Terpiłowski

terpil@umcs.pl

1 Department of Physical Chemistry-Interfacial Phenomena, Maria Curie Sklodowska University, Lublin, Poland graphene gaps were found. Quoting the researchers on for the materials can open a new way for rational design of the graphene-plasmonic hybrid structure in the case of surfaceenhanced Raman scattering. Song et al. (2017) obtained a superhydrophobic graphene structure on the stainless steel which was prepared by laser etching and then to obtain the pillar structure it was immersed in $\left(\mathrm{CH}_{3}\left(\mathrm{CH}_{2}\right)_{11} \mathrm{Si}\left(\mathrm{OCH}_{3}\right)_{3}\right)$. The graphene film was grown by chemical vapour deposition (Li et al. 2016) and then the graphene layer was transferred onto the prepared stainless steel surface (Barin et al. 2015). Due to this process they obtained the surface with the hierarchical structure of roughness dependent on laser etching of substrate material. Topography of the obtained materials was investigated by 3D confocal laser scanning and SEM images. Average roughness changed depending on the obtained structure and it was $3.8 \mu \mathrm{m}$ for the horseshoe structure and $10.2 \mu \mathrm{m}$ for the inverted hook one. Then the graphene film was deposited as the rose petal structured on the stainless steel plates the water contact angle was $154.3^{\circ}$ with strong water adhesion to the surface. These materials can be applied as smart materials and microfluidic devices in the future.

Graphene is a new material and it is still difficult to obtain uniform and big graphene foils. However, as it was mentioned above scientists work on future application of graphene in the composite structure. The literature reports 
more applications of graphene in the surface preparation (An et al. 2017; Yang et al. 2017; Tresca et al. 2017). Moreover, there is a lot of basic research about graphene wettability of which that by Raj et al. (2013) is worth mentioning. There are also some papers about molecular investigations of water behaviour on the graphene surface (Huang et al. 2017; Bagheri et al. 2017). In the Department of Physical ChemistryInterfacial Phenomena the investigations are carried out on designing the surface with specific properties (Terpiłowski et al. 2015), in collaboration with industry as far as specific surface properties are concerned (Terpiłowski et al. 2017). In this manuscript surface properties of graphene and graphene/diamond composites are discussed. These materials are used to prepare honing tools and we do not think only about not only prospective application of these materials. They are sent to one of our collaborators for testing under industrial conditions.

\section{Experimental}

\subsection{Sample preparation}

Basic material consists of $95 \%$ (wt $\%$ ) tungsten carbide, and about $4.75 \%$ of cobalt, $0.1 \%$ of niobium, $0.15 \%$ tallium. Powder materials are placed in a special form, base materials are placed on the bottom of the form and those enriched with petal graphene on the top (Institute of Electronic Materials Technology, ITME, Warsaw) (Stupiński 2011) powder (5 volume \% the layer) and in the second case graphene powder and $0.25-5$ carats of diamonds (Diamonds Market Antwerp, Belgium). Powder materials are bowed in an electric arc in the temperature range $900-1200{ }^{\circ} \mathrm{C}$ with the eletrical power $100 \mathrm{~kW}$ for $15 \mathrm{~min}$. The obtained tool has hardness of about 40-70 degrees in the Rockwell scale. The materials were obtained from the ZNDiS company (Diamond and Sintered Tools Factory, Kraśnik, Poland). The image of the obtained surface is shown in Fig. 1.

\subsection{Infrared RAMAN spectroscopy}

Spectra were prepared using the In Via Reflex reserchgrande microscope (Renishaw) with a single-grating spectrometer coupled to a research grade optical microscope.

\subsection{Scanning microscope images (SEM)}

Morphology was examined using the high distributive field emission scanning electron-ion microscope (FE-SEM) (Quanta 3D FEG, FEI) (BSED detector).

\subsection{Optical profilometry}

Surface images of the obtained materials and their roughness were analysed using an optical profilometer (Contour GT, Veeco) to have the same area as a droplet on the surface during the angle measurements. The recorded side profiles were indicative of complex shape of synthesised samples surface. While the simple roughness parameter $\mathrm{R}_{\mathrm{a}}$ (average roughness) was not adequate in this case, $R_{q}$ (root-mean-square roughness) and $\mathrm{R}_{\mathrm{t}}$ (the peak-to-valley distance calculated over the entire measured area) parameters were taken into consideration.

\subsection{Wettability}

\subsubsection{Contact angles}

To characterise wettability the advancing and receding contact angles were measured using the GBX (France) apparatus. In the first step a $6 \mu \mathrm{l}$ droplet was placed on the surface. The contact angles in the left and right sides of the droplet were measured using Win Drop++ program and they were averaged. Then $2 \mu \mathrm{l}$ of the tested liquid was sucked back into the syringe and the receding contact angle was measured in the same way. In the chamber the temperature was $20^{\circ} \mathrm{C}$ and the relative humidity $50 \%$. The plate was kept in the chamber for about $5 \mathrm{~min}$ before the measurements to obtain a proper temperature. The values of the contact angles shown in the graphs are the average from at least ten droplets.

\subsubsection{Apparent surface free energy}

From advancing and receding contact angles equilibrium contact angles were calculated using Eq. 1c proposed by Tadmor (Tadmor 2008a, b; Tadmor at al. 2017).

$\Gamma_{a} \equiv\left(\frac{\sin ^{3} \theta_{a}}{\left(2-3 \cos \theta_{a}+\cos ^{3} \theta_{a}\right)}\right)^{1 / 3}$
Fig. 1 Image of obtained surfaces

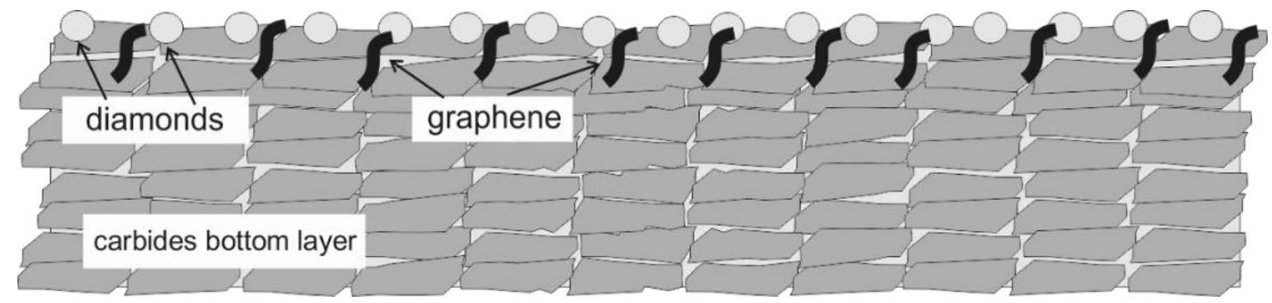


$\Gamma_{r} \equiv\left(\frac{\sin ^{3} \theta_{r}}{\left(2-3 \cos \theta_{r}+\cos ^{3} \theta_{r}\right)}\right)^{1 / 3}$

$\theta_{0}=\arccos \left(\frac{\Gamma_{a} \cos \theta_{a}+\Gamma_{r} \cos \theta_{r}}{\Gamma_{a}+\Gamma_{r}}\right)$

where: $\theta_{\mathrm{a}}$-the advancing contact angle, $\theta_{\mathrm{r}}$-the receding contact angle, $\Gamma_{\mathrm{a}}$-the advancing angle weight coefficient (Terpiłowski 2015), $\Gamma_{\mathrm{r}}$ - the receding angle weight coefficient (Terpiłowski 2015), $\theta_{0}$ - the calculated equilibrium contact angle.

Then the hysteresis (Eq. 2) (Chibowski 2002) approach used for calculation of apparent surface free energy

$\gamma_{S}^{\text {tot }}=\frac{\gamma_{L}\left(1+\cos \theta_{a}\right)^{2}}{\left(2+\cos \theta_{r}+\cos \theta_{a}\right)}$

where: $\gamma_{S}^{\text {tot }}$-the apparent surface free energy, $\gamma_{L}$-the liquid surface tension is transferred into (Chibowski and Terpiłowski 2009) (Eq. 3)

$\gamma_{s}=\frac{\gamma_{L}}{2}(1+\cos \theta)$

\section{Results and discussion}

The samples were cut into for $2 \times 2 \mathrm{~cm}$ plates. The examined samples in cross-section had two distinctive layers. In the case of surfaces with diamonds the upper layer was lighter while in the case of surfaces with graphene and diamond it was darker. In order to confirm that graphene and diamonds were obtained, Raman spectra of the tested materials were made on the surface. Also in the case of diamonds addition shiny elements can be seen on the surface. Using the optical microscope which is the part of Raman spectrometer sites of possible presence of graphene and diamonds were found (Figs. 2a, 3a, c). Spectra were taken of these places to confirm specific properties of the surface top. As can be seen from Fig. 2a two characteristic peeks for graphene were found. The first peak at about $1330 \mathrm{~cm}^{-1}$ which corresponds to the graphene edge structure and is known as disordered bands (Seung et al. 2017; Tuz Johra et al. 2014). The other one was found at about $1580 \mathrm{~cm}^{-1}$ and according to $\mathrm{Li}$ et al. (Li et al. 2017) this peak represents the vibrations in all $s p^{2}$ bonded carbon atoms, which is associated with the "defectfree" graphitic character. In the case of the other material a surface specific spectrum for the natural diamond structure was found. The characteristic peak of this structure is at about (Fig. 2b) $1332 \mathrm{~cm}^{-1}$ and this is a very sharp peak of diamond structure vibrations (Nasdala et al. 2016). Graphene is also present on this surface its spectrum can be seen in Fig. 3d and compared with the former material of about $2700 \mathrm{~cm}^{-1}$ peak was observed and it corresponds to the thickness of graphene presented on the matrix. Its presence can also indicate partial oxidation of graphene and vertical deposition of flakes ( $\mathrm{Li}$ et al. 2017; Ling et al. 2013).

In the case of scanning microscopy, the representative images were chosen. As can be seen in Fig. 4a the border between the bottom and top layers of the graphene clusters is visible seen in the top layer. They are present in the material quite irregularly and are of varied sizes. The bottom layer structure is uniform which can be seen in Fig. 4c. In the case of the other material more significant difference between the bottom and top layers is observed (Fig. 5a). Graphene

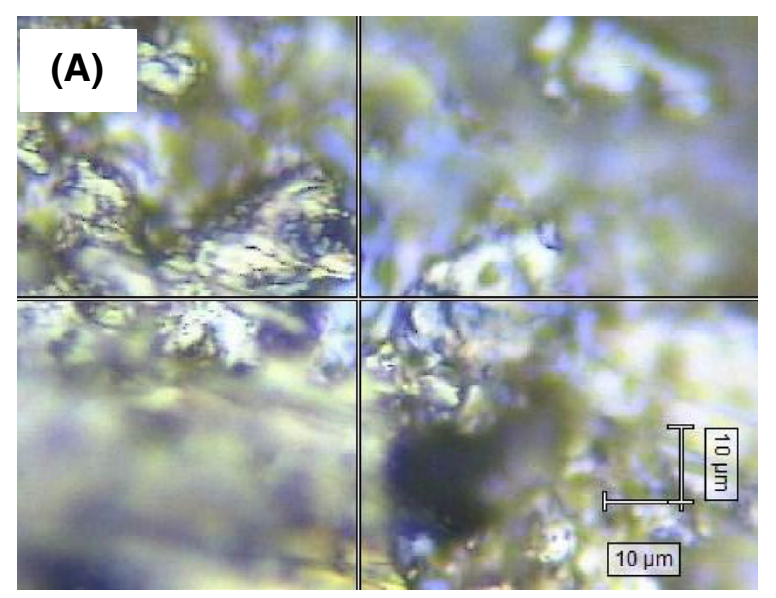

(B)

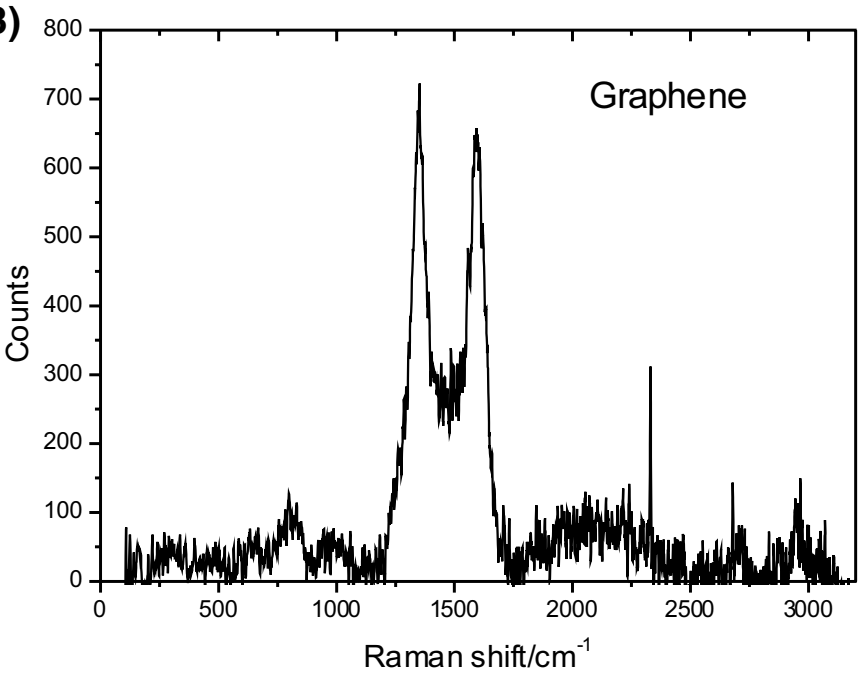

Fig. 2 a Optical microscope photo with the marked site from which the spectrum was taken, b Raman spectrum of graphene composites 

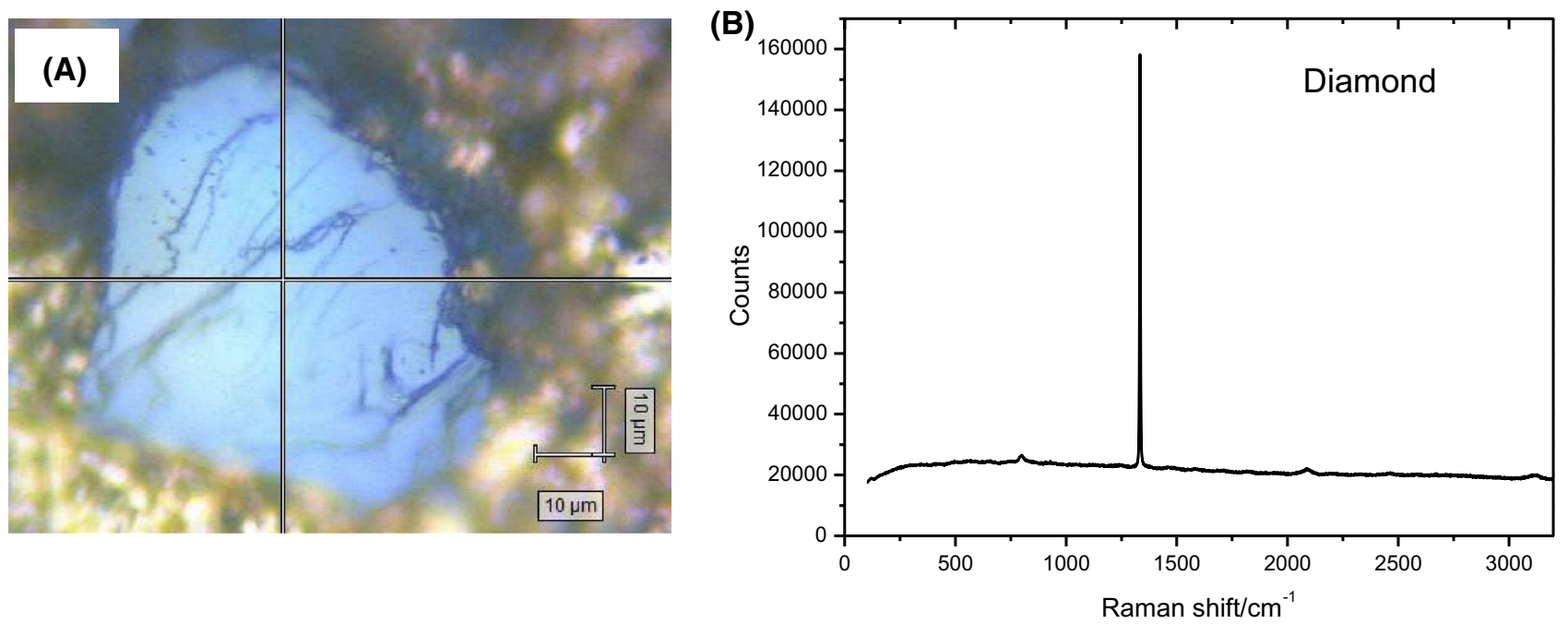

(D)
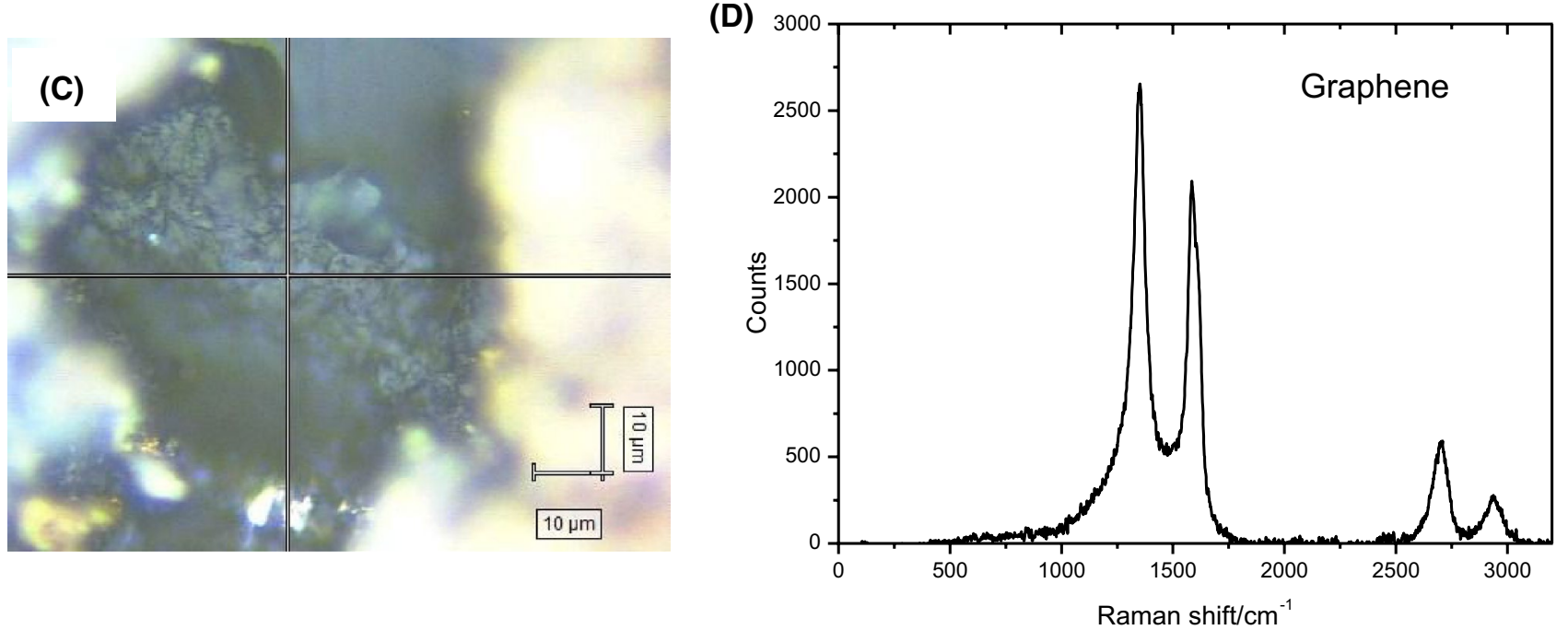

Fig. 3 a Optical microscope photo with the marked site from which the diamond spectrum was taken, $\mathbf{b}$ Raman spectra of diamond on the composite surface, $\mathbf{c}$ optical microscope photo with the marked site

place which the graphene spectrum was taken, $\mathbf{d}$ Raman spectra of graphene on the composite surface

clusters are found on the top layer (Fig. 5b). In the case of diamond, it should be mentioned that this material is not soldered. To keep the diamond on the surface it should be surrounded by carbide. Diamond particles used in the industry are of circular shape and the diamond particle is a round object (Fig. 5c).

Wettability of solid surface depends on the surface composition and surface roughness. Wettability was determined using $6 \mu$ volume droplets (Rymuszka et al. 2013) and the roughness was described using optical profilometry. A liquid droplet occupies the area of about a few square millimetres and profilometry data corelate well with the liquid behaviour on the surface. As can be seen in Fig. 6 the plate obtained with the graphene addition is rough. On the side profile

(Fig. 6b) on the surface some deep gaps, average roughness $2.2 \mu \mathrm{m}$ can be observed (Table 1). These gaps are distributed regularly which is evident from the value of $\mathrm{R}_{\mathrm{RMS}}$ index which is used to eliminate the influence on the average of one huge roughness. In this case its value is very close to the average, so it is possible to believe that gaps are distributed regularly and the whole material is homogeneous. Moreover, it was impossible to find differences between the roughness of bottom and top layers. A contrary situation is observed in the case of the second material. As can be seen in Fig. 7a if the optical profilometry image was taken from the plate side there are difference in the roughness as can be seen in Fig. 7b. However, the most interesting is the top layer and here one can see a rough structure. Roughness is distributed 

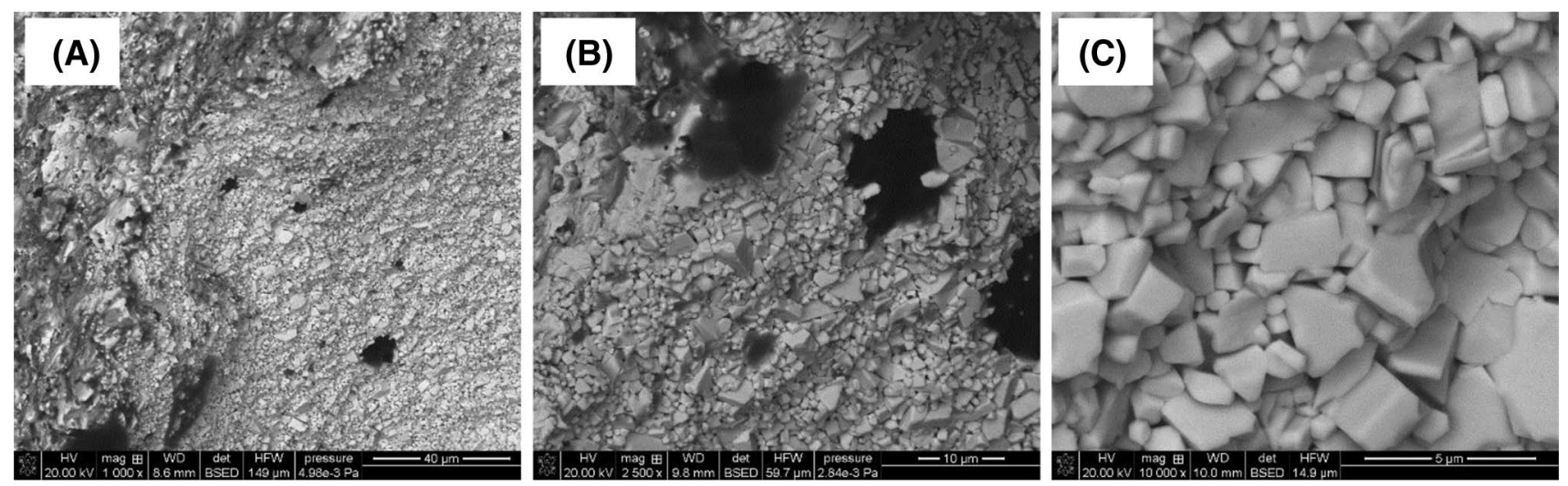

Fig. 4 SEM images of the composite obtained with the graphene addition $\mathbf{a} \times 1000$ magnification (border between the top graphene layer and the carbide layer), $\mathbf{b} \times 2500$ magnification (graphene in the top layer), $\mathbf{c} \times 10,000$ magnification (bottom layer without graphene)
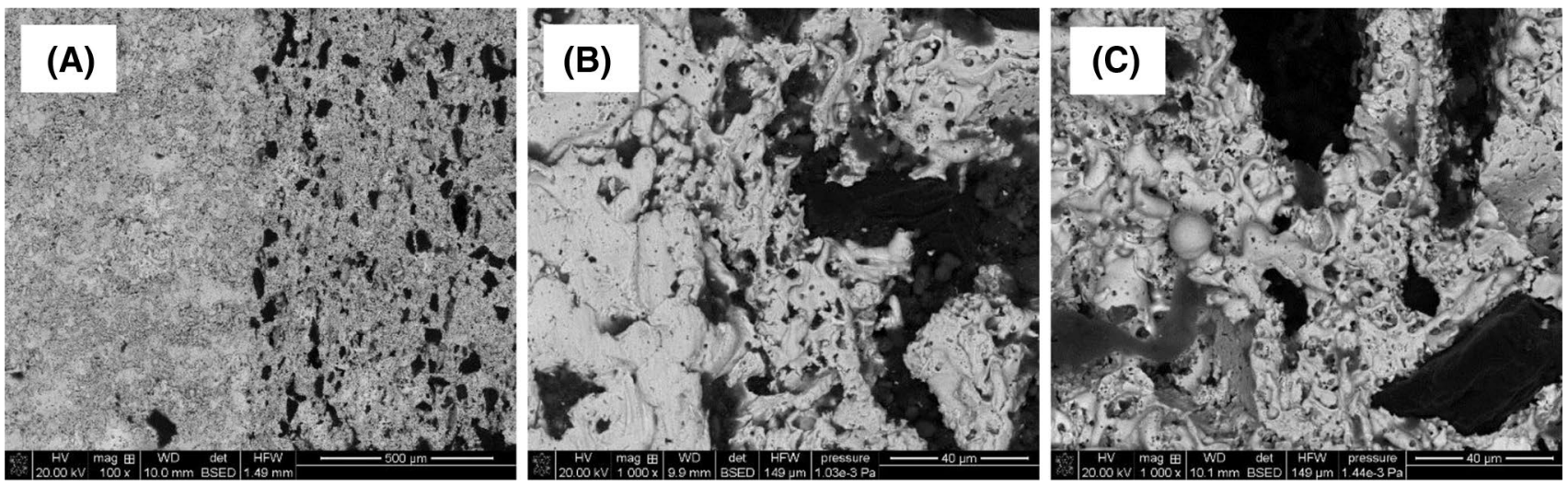

Fig. 5 SEM images of composite obtained with the graphene and diamonds addition $\mathbf{a} \times 100$ magnification (border between the top and the carbide layer), $\mathbf{b} \times 1000$ magnification (border between the top and the carbide layer), $\mathbf{c} \times 10,000$ magnification (top layer with graphene and diamonds)
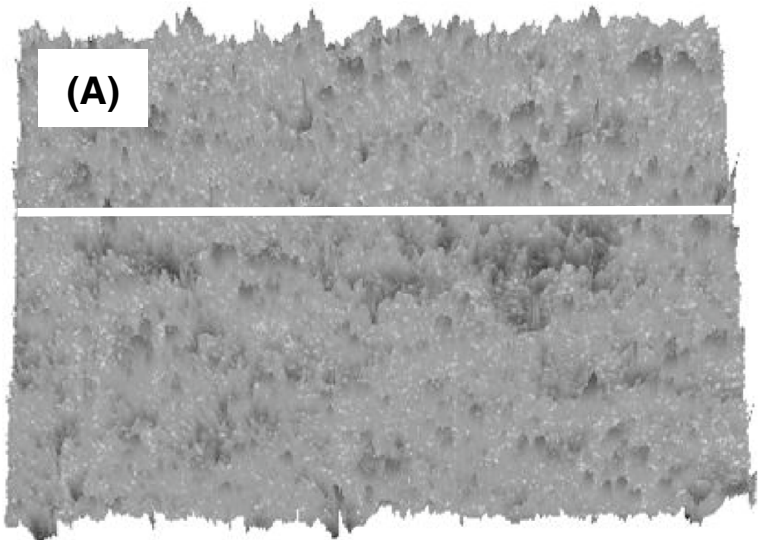

(B)

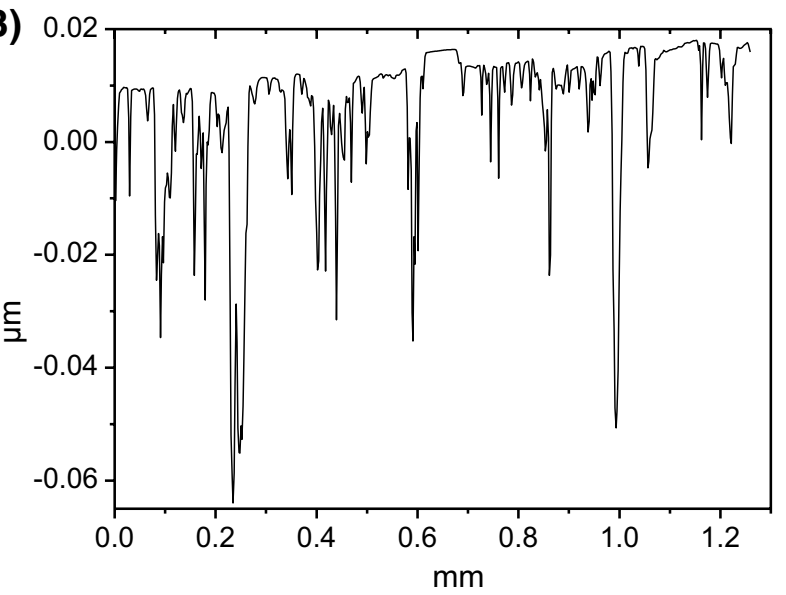

Fig. 6 a Optical profilometer 3D image $(0.9 \times 1.3 \mathrm{~mm})$, b side profile along the line seen in the 3D image 
Table 1 Roughness parameters of the examined samples

\begin{tabular}{lll}
\hline Graphene material & Roughness parameter $(\mu \mathrm{m})$ & $\begin{array}{l}\text { Graphene/ } \\
\text { diamonds } \\
\text { material }\end{array}$ \\
\hline 2.20 & $\mathrm{R}_{\mathrm{a}}$ & 13.70 \\
2.81 & $\mathrm{R}_{\mathrm{RMS}}$ & 18.30 \\
25.34 & $\mathrm{R}_{\mathrm{t}}$ & 114.7 \\
\hline
\end{tabular}

$R_{\mathrm{a}}$ the average roughness, $R_{\mathrm{q}}$ the quadratic mean of the surface roughness, $R_{\mathrm{t}}$ the maximum roughness height

more randomly (Fig. 7c, d). This structure was obtained by the diamond addition. The average roughness was $13.70 \mu \mathrm{m}$ and the difference between the deepest valley and the highest hill was $114.7 \mu \mathrm{m}$ (Table 1).

Wettability of the top layer of the obtained materials was determined with water (Milli-Q $18.2 \mathrm{~m} \Omega / \mathrm{cm}$ ) and diiodomethane (99\% Sigma-Aldrich Germany). The water

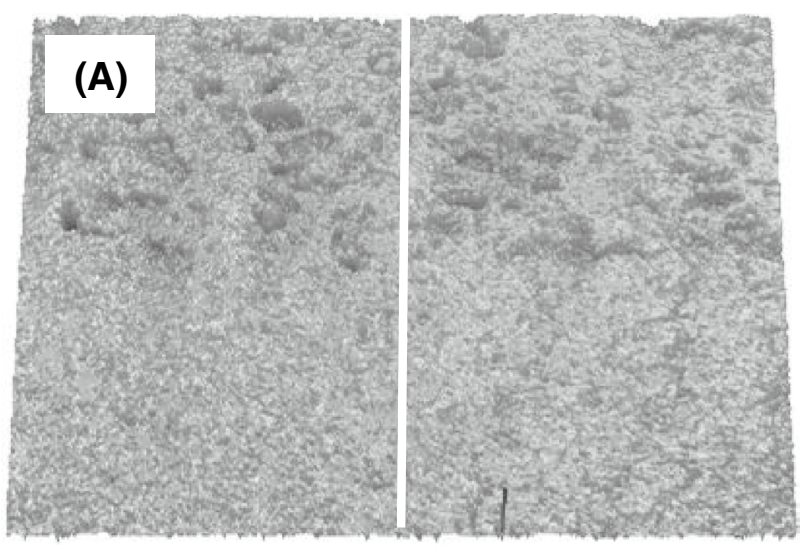

(B)
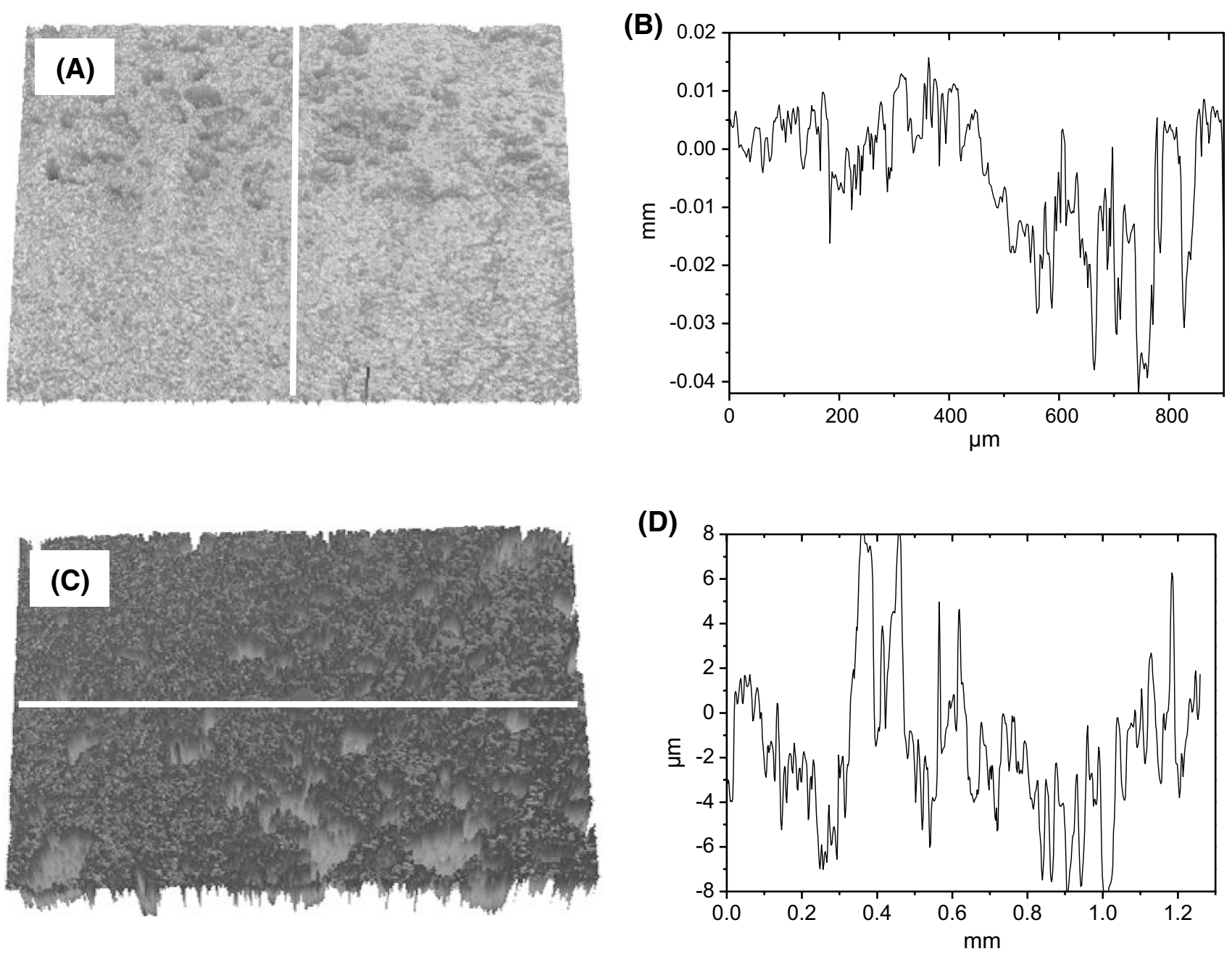

contact angle for smooth graphene according to CyuangJhang et al. (2016) was about $80^{\circ}$, but for the material where graphene was deposited on the carbon plate it was $61.1^{\circ}$. Just after taking it out from vacuum it increased to $86.5^{\circ}$ and after the exposure to ambient air it decreased to $61.4^{\circ}$ (Lai et al. 2014). Taking this data into account it can be clearly seen that graphene contact angle depends largely on the condition where it was measured and because of two-dimensional structure also on the support plate where the graphene petal is placed during the contact angle measurements. As for the materials under consideration the advancing water contact angles were $61.5 \pm 3.6^{\circ}$ and $65.5 \pm 1.8^{\circ}$ for the first and second materials respectively (Fig. 8). Considering the water contact angle value these materials should be treated as hydrophilic because the water contact angle is lower than $90^{\circ}$. For description of wettability not only contact angles are used. The second factor is the apparent surface free energy. Calculation of

Fig. 7 a Optical profilometer 3D image $(0.9 \times 1.3 \mathrm{~mm})$ (border between the bottom and top layers), b side profile along the line seen in the 3D image, $\mathbf{c} 3 \mathrm{D}$ image of graphene/diamond top layer, $\mathbf{d}$ side profile along the line seen in the 3D image on the left 


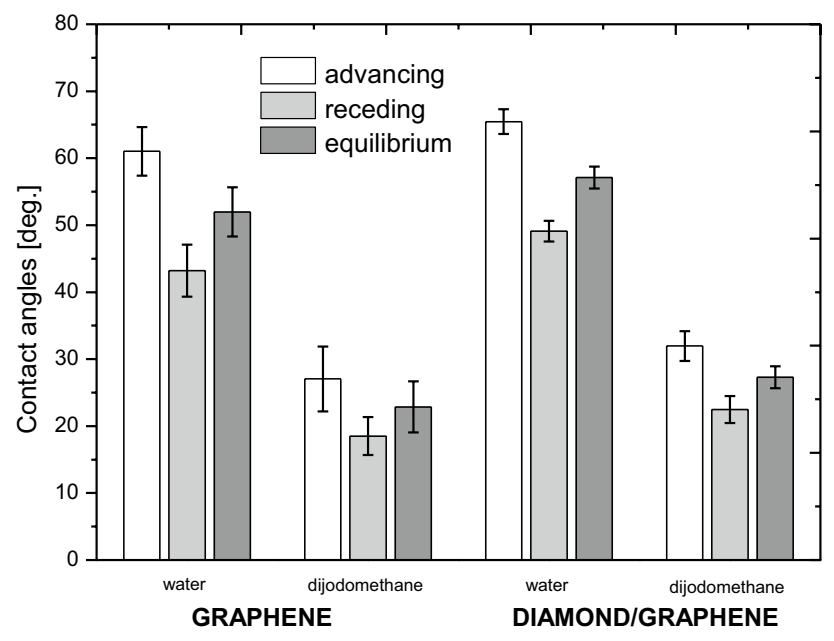

Fig. 8 Measured advancing, receding and calculated equilibrium contact angles for the composite surfaces

energy is based on the Young (1805) assumption, the contact angle known from his equation should be measured under equilibrium conditions. The liquid droplet should be in the equilibrium with its vapour but without adsorption on the surface. These conditions are impossible to obtain experimentally. Because of that the equilibrium contact angles were calculated from the Tadmor (Tadmor 2008a, b; Tadmor et al. 2017) theory. Moreover, classical wettability of rough hydrophobic surfaces is considered using the Wenzel (1936) theory, however, looking at the side profiles (Figs. 6b, 7d) and knowing liquids properties for wettability of these materials there should be used the theory proposed by Bormashenko (Bormashenko 2011). It describes wettability of rough surface, the roughness can be partially wetted by liquid. It means that liquid does not penetrate all "cracks" on the surface. Also because of that using the equilibrium contact angle is justified. The apparent surface free energy was calculated using the equilibrium contact angles. If the diiodomethane surface tension is assumed to be $50.8 \mathrm{~mJ} / \mathrm{m}^{2}$ and interactions are due to dispersive forces. The large value of apparent free energy (Fig. 9) obtained from the diiodomethane contact angle proves large dispersive interactions on the surface. Apparent surface free energy calculated from the water contact angle is $58.8 \pm 1.8$ and $56.2 \pm 0.9 \mathrm{~mJ} / \mathrm{m}^{2}$ from diiodomethane. The energy calculated from water is about $8 \mathrm{~mJ} / \mathrm{m}^{2}$ higher than that calculated from the diiodomethane contact angles. Large value of dispersive interactions on the surface is characteristic of hydrophobic or superhydrophobic surfaces (Chibowski 2011). Therefore, in the case of the examined surface, roughness structure is of crucial importance for wettability.

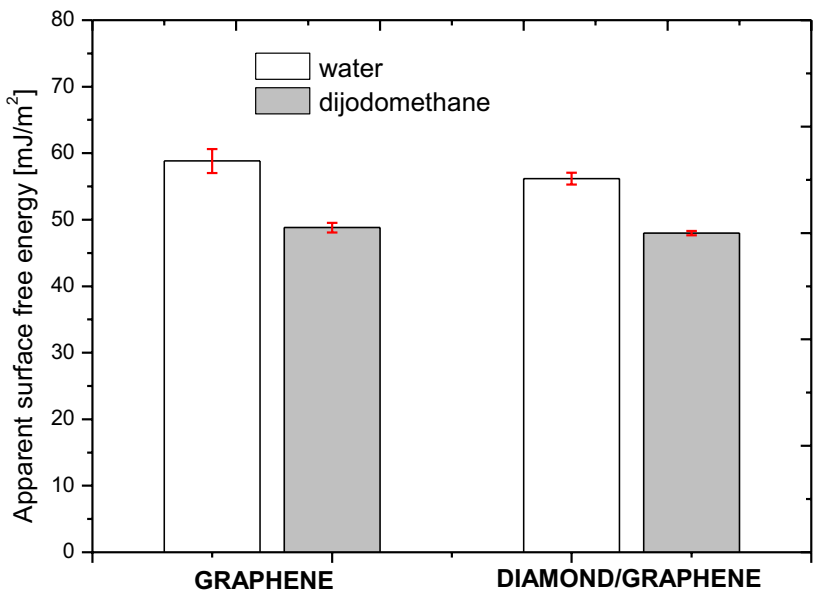

Fig. 9 Apparent surface free energy of the tested samples

\section{Conclusions}

New materials with a specific top layer were obtained. Existence of graphene and diamonds was proved by Raman spectroscopy. Because of that based on the SEM images one can think that dark gaps on the surface are graphene and those circular diamond. The obtained materials have rough structure in general of micrometer scale also exhibiting some nano roughness. Wettability of surfaces was investigated using polar (water) and nonpolar (diiodomethane) liquids. The diamonds addition affects roughness change and wettability as can be seen in the case of polar liquid. Describing wettability based on the equilibrium contact angles can provide information about apparent surface free energy which is significant in the precision industry. The industrial tests show $15 \%$ improvement durability of these materials compared to those without graphene.

Acknowledgements The research was carried out with the equipment purchased owing to the financial support of POIG.02.01.00-06-024/09 and POIR.01.02.00-00-0004/16 programs.

Open Access This article is distributed under the terms of the Creative Commons Attribution 4.0 International License (http://creativeco mmons.org/licenses/by/4.0/), which permits unrestricted use, distribution, and reproduction in any medium, provided you give appropriate credit to the original author(s) and the source, provide a link to the Creative Commons license, and indicate if changes were made.

\section{References}

An, S., Joshi, B.N., Lee, J.G., Lee, M.W., Kim, Y.I., Kim, M., Jo, H.S., Yoon, S.S.: A comprehensive review on wettability, desalination, and purification using graphene-based materials at water interfaces. Catal. Today 295, 14-25 (2017) 
Bagheri, S., Shameli, A., Fakhrpour, G.: Low-dimensional systems and nanostructures. Physica E 90, 123-130 (2017)

Barin, G.B., Song, Y., Gimenez, I.F., Filho, A.G.S., Barreto, L.S., Kong, J.: Optimized graphene transfer: influence of polymethylmethacrylate (PMMA) layer concentration and baking time on graphene final performance. Carbon 84, 82-90 (2015)

Bormashenko, E.: General equation describing wetting of rough surfaces. J. Colloid. Interface Sci. 360, 317-319 (2011)

Chibowski, E.: Contact angle hysteresis due to a film present behind the drop. In: Mittal, K., K.L. (eds.) Contact Angle, Wettability and Adhesion, vol. 2, pp. 265-288. VSP, Utrecht (2002)

Chibowski, E.: Apparent surface free energy of superhydrophobic surfaces. J. Adhes. Sci. Technol. 25(12), 1323-1336 (2011)

Chibowski, E., Terpiłowski, K.: Comparison of apparent surface free energy of some solids determined by different approaches. In: Mittal, K.L. (ed.) Contact Angle, Wettability and Adhesion, vol. 6, pp. 283-300. VSP, Boston (2009)

Cyuang-Jhang, W., Yueh-Feng, L., Wei-Yen, W., Yu-Jane, S., HengKwong, T.: Contact angle hysteresis on graphene surfaces and hysteresis-free behavior on oil-infused graphite surfaces. Appl. Surf. Sci. 385, 153-161 (2016)

Hadad, C., Ke, X., Carraro, M., Sartorel, A., Bittencourt, C., van Tendeloo, G., Bonchio, M., Quintanae, M., Prato, M.: Positive graphene by chemical design: tuning supramolecular strategies for functional surfaces. Chem. Commun. 50, 885-887 (2014)

Huang, C., Xu, F., Sun, Y.: Effects of morphology, tension and vibration on wettability of graphene: a molecular dynamics study. Comput. Mater. Sci. 139, 216-224 (2017)

Lai, C.Y., Tang, T.C., Amadei, C.A., Marsden, A.J., Verdaguer, A., Wilson, N., Chiesa, M.: A nanoscopic approach to studying evolution in graphene wettability. Carbon 80, 784-792 (2014)

Li, X.S., Combo, L., Ruoff, R.S.: Graphene films: synthesis of graphene films on copper foils by chemical vapor deposition. Adv. Mater. 28, 6247-6252 (2016)

Li, Z., Yang, W., Wu, Y., Wu, S., Cai, Z.: Role of humidity in reducing the friction of graphene layers on textured surfaces. Appl. Surf. Sci. 403, 362-370 (2017)

Ling, X., Wu, J., Xie, L., Zhang, J.: Graphene-thickness-dependent graphene-enhanced raman scattering. J. Phys. Chem. C 117, 2369-2376 (2013)

Marcano, D.C., Kosynkin, D.V., Berlin, J.M., Sinitskii, A., Sun, Z., Slesarev, A., Alemany, L.B., Lu, W., Tour, J.M.: Improved synthesis of graphene oxide. ASC Nano 4, 8, 4806-4814 (2010)

Nasdala, L., Steger, S., Reissner, C.: Raman study of diamond-based abrasives, and possible artefacts in detecting UHP microdiamond. Lithos 265, 317-327 (2016)

Quintana, M., Spyrou, K., Grzelczak, M., Browne, W.R., Rudolf, P., Prato, M.: Functionalization of graphene via 1,3-dipolar cycloaddition. ASC Nano 4(6), 3527-3533 (2010)

Raj, R., Maroo, S.C., Wang, E.N.: Wettability of grapheme. Nano Lett. 13, 1509-1515 (2013)

Rymuszka, D., Terpiłowski, K., Hołysz, L.: Influence of volume drop on surface free energy of glass. Ann. UMCS LXVIII, 121-132 (2013)
Seung, B.S., Huang, F., Tae-Sung, B., Wong-Ki, H.: Wettability effects of graphene oxide aqueous solution in photodetectors based on graphene oxide/silicon heterojunctions via ultraviolet ozone treatment. J. Alloys Compd. 698, 384-389 (2017)

Song, Y., Liu, Y., Jiang, H., Zhang, Y., Han, Z., Ren, L.: Biomimetic super hydrophobic structured graphene on stainless steel surface by laser processing and transfer technology. Surf. Coat. Technol. 328, 152-160 (2017)

Strupinski, W., Institute of Electric Materials Technology: Method of Graphene Manufacturing. European patent EP 2392547 A2. (Dec 7) (2011)

Tadmor, R.: Line energy and the relation between advancing, receding, and young contact angles. Langmuir 20(18), 7659-7664 (2008a)

Tadmor, R.: Line energy, line tension and drop size. Surf. Sci. 622(14), L108-L111 (2008b)

Tadmor, R., Das, R., Gulec, S., Liu, J., N'guessan, H.E., Shah, M., Shah, M., Wasnik, P.S., Yadav, S.B.: Solid-liquid work of adhesion. Langmuir 30(15), 3594-3600 (2017)

Terpiłowski, K.: Surface free energy of superhydrophobic materials obtained by deposition of polymeric particles on glass. In: Mittal, K.L. (ed.) Advances in Contact Angle, Wettability and Adhesion, vol. 2, pp. 381-395. Wiley, New York (2015)

Terpiłowski, K., Rymuszka, D., Goncharuk, O.V., Sulym, I.Y., Gun'ko, V.M.: Wettability of modified silica layers deposited on glass support activated by plasma. Appl. Surf. Sci. 353, 843-850 (2015)

Terpiłowski, K., Rymuszka, D., Hołysz, L., Ilnicki, M.: Surface properties of metal alloys used in aviation after plasma treatment. Surf. Interface. Anal. 49, 647-653 (2017)

Tresca, C., Verbitskiy, N.I., Fedorov, A., Grüneis, A., Profeta, G.: Alloyed surfaces: new substrates for graphene growth. Surf. Sci. 665, 28-31 (2017)

Tuz Johra, F., Lee, J.L., Jung, W.G.: Facile and safe graphene preparation on solution based platform. J. Ind. Eng. Chem. 20, 2883-2887 (2014)

Wenzel, R.N.: Resistance of solid surfaces to wetting by water. Ind. Eng. Chem. 28, 988-994 (1936)

Yang, S., Chen, L., Wang, C., Rana, M., Ma, P.C.: Surface roughness induced superhydrophobicity of graphene foam for oil-water separation. J. Colloid Interface Sci. 508, 254-262 (2017)

Young, T.: An essay on the cohesion of fluids. Philos. Trans. 95, 65-87 (1805)

Zhao, Y., Liu, X., Wang, M., Zhang, L., Chu, B., Yang, C., Liu, Y., Zhou, D., Lu, Y.: Constructing sub-10-nm gaps in graphene-metal hybrid system for advanced surface-enhanced raman scattering detection. J. Alloys Compd. 720, 139-146 (2017)

Publisher's Note Springer Nature remains neutral with regard to jurisdictional claims in published maps and institutional affiliations. 